\title{
Research on the High-quality Development of Manufacturing Industry in Shandong Province Under the Background of Kinetic Energy Transfer
}

\author{
Yigeng Li*, Zhi Chen \\ Department of Accounting, Shandong Technology and Business University, Yantai, China
}

Email address:

535593872@qq.com (Yigeng Li), chenzhi0925@163.com (Zhi Chen)

${ }^{*}$ Corresponding author

\section{To cite this article:}

Yigeng Li, Zhi Chen. Research on the High-quality Development of Manufacturing Industry in Shandong Province Under the Background of Kinetic Energy Transfer. Science Innovation. Vol. 9, No. 1, 2021, pp. 19-25. doi: 10.11648/j.si.20210901.14

Received: January 30, 2021; Accepted: March 3, 2021; Published: March 9, 2021

\begin{abstract}
Under the background of the shift in driving forces, Shandong Province's manufacturing industry has entered a critical period of high-quality development, and it is urgent to construct a scientific index evaluation system to evaluate the state of development. In order to achieve this goal, this paper systematically combs the past research on the development of high-quality economy, combined with the connotation, concept and policy of high-quality development of manufacturing industry and considered the actual situation of the development of manufacturing industry in Shandong Province. A High-quality development index evaluation system of manufacturing industry in Shandong province with 20 indicators was established, including six dimensions of quality benefit, innovation-driven, environmental protection, coordinated development, opening up to the outside world and social feedback. Then, based on the collected data and starting from the above six dimensions, a comprehensive evaluation is made on the high-quality development of manufacturing industry in Shandong province in the five years from 2014 to 2018. Finally, based on the calculated comprehensive score, analyzing the high-quality development of manufacturing industry in Shandong province from 2014 to 2018, and putting forward reasonable Suggestions according to the existing deficiencies. The index evaluation system constructed in this paper is of great practical significance to the evaluation of the high-quality development of manufacturing industry in Shandong province in the future.
\end{abstract}

Keywords: Manufacturing, High-quality Development, EWM, Evaluation Indicators

\section{新旧动能转换背景下山东省制造业高质量发展研究}

\author{
李亦耕", 陈智 \\ 山东工商学院会计学院, 烟台, 中国 \\ 邮箱 \\ 535593872@qq.com (李亦耕), chenzhi0925@163.com(陈智)
}

摘要: 在新旧动能转换的大背景下, 山东省制造业正处于高质量发展的关键时期, 亟需构建一套科学的指标评价体系 对其发展状况做出评价。为实现这一目的, 本文在系统梳理以往对经济高质量发展评价研究的基础之上, 综合制造业 高质量发展内涵及相关理念、政策, 考虑山东省制造业发展的实际状况, 构建了包含质量效益、创新驱动、绿色环保、 协调发展、对外开放和社会回馈六个维度，共计20项指标的山东省制造业高质量发展指标评价体系。而后，以搜集到 的相关数据为基础, 采用熵权法从上述六个维度出发, 对2014-2018年五年间山东省制造业高质量发展状况做出全面评 价。最后, 以计算出的综合得分为基础, 分析山东省制造业2014-2018五年间高质量发展状况, 根据存在的不足提出合 理建议。本文现阶段构建的指标评价体系，对山东省日后开展制造业高质量发展评价工作具有重要实践意义。 
关键词: 制造业, 高质量发展, 熵权法, 指标评价

\section{1. 研究背景}

为了激发我国经济活力, 解决供给侧与需求侧矛盾, 党中央适时提出了以新旧动能转换作为中国经济转型升 级的内部驱动力, 实现中国经济高质量发展的强国战略。 山东省作为新旧动能转换综合实验区, 加快实施新旧动能 转换, 既是推动山东省经济高质量发展的必然选择, 也是 新时代背景下的重大机遇, 同时也是一项艰巨的挑战。作 为经济发展大省, 制造业在山东省工业生产方面具有举足 轻重的地位, 对山东省规模以上工业利润总额的贡献率达 到 $90 \%$ 以上, 是山东省成为超级工业强省的有力保障, 但 一直以来山东省制造业还存在着传统产业占比大, 创新能 力不突出等问题。那么在新旧动能转换等相关政策的推动 下, 制造业是否实现了高质量发展呢? 长期以来, 相关研 究仍较多停留在宏观层面, 主要围绕经济高质量发展内涵、 实现路径以及指标评价体系的构建等方面来展开, 对于制 造业高质量发展评价探讨的较少。[1]

经济高质量发展的内涵丰富, 至今学界对其内涵未形 成统一的界定与表述。田秋生表示, 经济高质量发展是由 于我国经济发展和社会主要矛盾发生变化, 因此需要对经 济发展的方向、重点和目标做出一次战略调整; [2]林兆木 认为, 经济高质量发展是在体现创新、协调、绿色、开放、 共享五大理念的基础上, 能够更好满足人民日益增长的美 好生活需要的发展; [3]金碚则提出, 经济高质量发展是要 “不失本真, 勿忘质量”, 即改善经济质量, 将经济工作转 向供给侧结构性改革。[4]

在如何选择实现经济高质量发展的路径方面, 研究相 对丰富与成熟。例如以解放思想、深化改革、扩大开放和 明确产业方向为切入点, 助力实现经济高质量发展; [5] 以创新驱动、市场化改革、对外开放和提高人民生活质量 为方向，推动经济实现高质量发展； [6]通过把握“第二机 会窗口”，充分利用新一轮的技术革命，最终实现经济的 高质量发展。[7] 上述相对全面且颇具创新性的研究结果, 已然为我国实现经济高质量发展这一目标指明了方向。

构建经济质量指标评价体系一直是经济研究方面的 热点领域。早期研究从社会发展、环境质量、软实力和民 生四个维度对区域经济发展质量做出评价。[8]后期随着经 济高质量发展概念的提出以及对其内涵的不同理解, 逐步 出现了基于微观、中观和宏观三个层面构建的诸如产品质 量、产业经济质量以及宏观均衡质量共计十二项指标的评 价体系; [9]以及通过划分高质量供给、高质量需求、发展 效率、经济运行和对外开放五个维度, 构建经济高质量发 展总指数。[10]

然而, 为了科学评价制造业领域高质量发展状况, 需 要构建与制造业高质量发展相关的评价体系。科学、客观 的评价体系能够对制造业发展提供强有力的监控, 是反映 制造业高质量发展的“晴雨表”, 是诊断制造业发展症结的 有力工具, 对推动制造业高质量发展具有重要的理论和现 实意义。张文会、乔宝华基于朱启贵教授于《文汇报》刊
登的“建立推动高质量发展的指标体系”一文, 初步构建了 七大项、囊括二十七小项的指标评价体系; [11]之后又有 刘欣欣、孙良泉等从质量、创新、效益三大维度探索搭建 了山东省制造业高质量发展指标评价体系。[12]遗憾的是, 相关研究仅仅停留于指标评价体系的搭建, 而鲜有涉及到 利用该指标评价体系做出具体的数据测算。

综上所述, 虽然已有研究为本文提供了较为充足的研 究基础并拓展了研究视角, 但仍然存在以下问题: 首先, 现有研究多着重于经济高质量发展指标评价体系的构建, 对后续的指标落实及测算工作涉及不多; 其次, 对于有着 “实体经济基础”之称的制造业以及有着“超级工业强省” 之称的山东省而言, 与制造业高质量发展相关的研究并不 多见, 利用指标评价体系对制造业高质量发展状况进行量 化评价更是少之又少。因此, 本文拟选取山东省制造业为 研究对象, 在建立科学的指标评价体系基础之上, 搜集 2014-2018年五年的数据, 通过对指标的量化处理, 对其 制造业高质量发展状况进行科学、客观的评价, 从而补充 相关研究的不足。

\section{2. 制造业高质量发展的理论模型}

根据中国政府在十三五规划、党的十九大报告和 《中国制造2025》等一系列关于实现制造业高质量发展 的规章制度中提出的要求, 以“创新、绿色、协调、开 放、共享”五大发展理念为指引, 本文从质量效益、创 新驱动、绿色环保、协调发展、对外开放和社会共享五 个一级指标入手, 建立山东省制造业高质量发展的理论 模型, 并着手构建关于山东省制造业上市公司高质量发 展指标评价体系。

\section{1. 质量效益}

使制造业行业整体的质量效益得到提升, 是制造业高 质量发展的终极目的, 无法得到良好质量效益反馈的高质 量发展无疑是存在问题的。因此, 对制造业的传统绩效指 标做出评价, 依旧是高质量发展背景下评价制造业发展状 况的重要举措。因此本文考虑设立总资产贡献率、成本费 用利润率和资产负债率三项二级指标对山东省制造业高 质量发展下的经济效益水平做出考核。

\section{2. 创新驱动}

现阶段, 山东省制造业呈现“大而不强”的态势, 而创 新是推动制造业“由大到强”的核心因素。《中国制造2025》 中提出要坚持把创新摆在制造业发展全局的核心位置, 走 创新驱动的发展道路; 而“五大发展理念”更是将创新列为 五大发展理念之首, 强调其有着统领全局的意义。因此, 本文考虑设立制造业研发经费投入强度、制造业研发人员 投入强度和人均发明专利数三项二级指标, 用来对山东省 制造业的创新情况做出评价。 


\section{3. 绿色环保}

长期以来, 我国制造业在粗犷的发展模式下得到了迅 速发展, 但与此同时也对生态环境造成了巨大的负面影响。 环境政策以及资源的不断收紧要求我国制造业必须与资 源环境相协调, 《中国制造2025》与“五大发展理念”同样 要求必须在绿色环保与可持续性的前提下推动制造业的 高质量发展。因此, 本文考虑设立节能环保支出比例、单 位工业增加值能耗、单位工业产值废水排放量和单位工业 产值固体废物排放量四项二级指标对山东省制造业的绿 色发展状况做出评价。

\section{4. 协调发展}

通过《中国制造2025》和“五大发展理念”可以总结得 到, 协调发展强调多方面、各层次、全方位的动态平衡, 其最终目的是实现制造业整体实力的提升。这就要求制造 业高质量发展要通过加大区域协调力度、优化产业结构升 级、提高生产效率和建设优质品牌等多角度来实现。例如 通过发展高技术制造业来逐渐推动传统行业的产业升级、 由要素驱动的“粗狂式增长”转变为提高全要素生产率的 “集约式增长”、完善质量监管体系并推动先进的质量管理 技术和方法等。因此，本文考虑设立高技术产业主营业务 收入比重、制造业全员劳动生产率、制造业人均产值和山 东省制造业500强占比四项指标对山东省制造业协调发展 状况做出评价。

\section{5. 对外开放}

在经济全球化的大背景下，各国经济“相通则共进， 向闭则共退”。经济的高质量发展势必要与对外开放这一 理念融会贯通、相辅相成, 而制造业作为实体经济的基础, 其对外开放程度也应当作为评价制造业高质量发展状况 的一项重要依据。基于此, 本文考虑设立高技术产业出口 总额比重和制造业出口交货值比重两项指标对山东省制 造业高质量发展的对外开放程度做出评价。

\section{6. 社会共享}

五大发展理念中的“共享”理念，是指必须坚持“发展 为了人民、发展依靠人民、发展成果由人民共享”。这一 理念可以在制造业产品的高质量、制造业从业者的收入水
平以及制造业行业纳税状况中得以体现。基于此, 考虑到 制造业在山东省的重要地位, 若制造业整体能实现高质量 发展, 则理应对社会做出重大贡献、创造巨大的社会价值, 最终达到共享式发展的目的。因此, 本文考虑选取制造业 产品质量合格率、制造业人均工资、制造业工资占比以及 制造业利税总额四项指标来衡量山东省制造业高质量发 展对社会做出的贡献。

\section{3. 制造业高质量发展指标评价体系的构建}

\section{1. 指标评价体系构建原则}

首先是科学性与可操作性相结合原则。在构建指标评 价体系时应当充分考虑制造业高质量发展的要求及特点, 对指标进行选取时应当做到客观科学、不重复不矛盾。应 当结合现有以及正在使用的指标, 优先考虑有统计制度支 撑的指标, 使数据可靠、稳定并易于获取[13]。若选取的 指标没有相应的统计基础支撑，导致无法有效搜集数据， 或是统计成本太高, 都会削弱构建指标体系的现实意义。

其次是可理解性与一致性相结合原则。应按照易于理 解的原则设计评价指标。指标体系本身就是一种抽象和简 化, 若因面面俱到而设计的过于繁杂, 就失去了采用指标 体系简化认知的意义。在一致性方面, 应当确保制造业高 质量发展指标体系的设计与评价目标相一致。[14]针对每 一个评价目标, 选取最具代表性且相对独立的指标来评价 所选目标的关键方面。

最后是重要性与独立性相结合原则。制造业高质量发 展指标评价体系的构建不可能涵盖所有指标, 因此构建指 标时应做到“重点因素重点突出”。此外, 在指标评价体系 构建过程中, 要尽量降低各个指标间的关联度, 做到相对 独立, 从而使评价结果的准确性得到保障。

表1设立的指标, 包含正向指标与负向指标。诸如总 资产贡献率、制造业研发经费投入强度、节能环保支出比 例、制造业人均产值、制造业出口交货比重和制造业利税 总额等指标, 皆为正向指标, 数值越大表示制造业在质量 效益、创新驱动、绿色环保、协调发展、对外开放和社会 回馈六个方面的表现越好; 与之相反的是资产负债率、单 位工业增加值能耗、单位工业产值废水排放量和单位工业 产值固体废物排放量四项负向指标, 其数值越大反映制造 业在质量效益、绿色环保两方面的表现越差。

\section{2. 指标评价体系构建}

表1 山东省制造业高质量发展指标评价体系。

\begin{tabular}{lllll}
\hline 一级指标 & 编号 & 二级指标 & 指标解释 & 方向 \\
\hline & 1 & 总资产贡献率 & (利润总额+税金总额+利息支出)/平均资产总额 & + \\
质量效益 & 2 & 成本费用利润率 & 利润总额/成本费用总额 & + \\
& 3 & 资产负债率 & 负债总额/资产总额 & + \\
& 4 & 制造业研发经费投入强度 & 制造业R\&D经费支出/制造业主营业务收入 & + \\
创新驱动 & 5 & 制造业研发人员投入强度 & 制造业R\&D员/制造业从业人员 & + \\
& 6 & 人均发明专利数 & 制造业发明专利数/制造业R\&人员 & - \\
& 7 & 节能环保支出比例 & 环保支出/地方一般公共预算支出 & - \\
绿色环保 & 8 & 单位工业增加值能耗 & 能源消耗 (标准煤)/工业增加值 & - \\
& 9 & 单位工业产值废水排放量 & 工业废水排放总量/工业总产值 & - \\
& 10 & 单位工业产值固体废物排放量 & 工业固体废物排放总量/工业总产值 & + \\
\hline
\end{tabular}




\begin{tabular}{lllll}
\hline 一级指标 & 编号 & 二级指标 & 指标解释 & 方向 \\
\hline & 11 & 高技术产业主营业务收入比重 & 高技术产业主营业务收入/制造业主营业务收入 & + \\
& 12 & 制造业全员劳动生产率 & 工业增加值制造业贡献部分/制造业从业人数 & + \\
协调发展 & 13 & 制造业人均产值 & 工业总产值制造业贡献部分/制造业从业人数 & + \\
& 14 & 山东省制造业500强占比 & 山东省制造业上榜数/全国制造业500强 & + \\
对外开放 & 15 & 高技术产业出口总额比重 & 高技术产业出口总额比重/制造业总产值 & + \\
& 16 & 制造业出口交货值比重 & 制造业出口交货值/规模以上工业出口交货值 & + \\
& 17 & 产品质量合格率 & 产品质量合格率 & + \\
社会共享 & 18 & 制造业人均工资 & 制造业工资总额/制造业从业人数 & + \\
& 19 & 制造业工资占比 & 制造业工资总额/全行业工资总额 & + \\
& 20 & 制造业利税总额 & 制造业企业利税总额 & + \\
\hline
\end{tabular}

\section{4. 山东省制造业高质量发展评价}

\section{1. 数据来源}

本文通过搜集山东省2014-2018年的制造业发展数据, 根据“五大发展理念”、“高质量发展”的提出时间并结合数 据可靠性、可行性等原则，对山东省制造业高质量发展状 况进行评价分析。数据均来自于《中国统计年鉴》、《山 东省统计年鉴》以及相关网站。在对相关数据进行归纳梳 理后, 使用SPSSAU平台进行数据的处理、分析与综合评 价。

\section{2. 确定权重}

权重的确定方法包括主观赋权法以及客观赋权法。主 观赋权法包括专家调查法、层次分析法等, 其优点是可以 根据专家自身的经验合理确定权重的排序，具有很强的实 效性, 然而权重的确定缺乏客观依据导致客观性较差。客 观赋权法主要包括模糊综合评价法、聚类分析法、因子分
析法和熵权法。模糊综合评价法用于解决各种难以量化的 定性问题, 但是主观性过强; 聚类分析法具有较好的客观 性, 但数据分析过程受到样本量的限制; 因子分析法是通 过提取主成分, 将之前较多的指标化繁为简, 有效解决信 息重叠, 但分析过程要求样本量至少大于指标数量, 因此 同样受到样本量的限制; 熵权法则是利用原始数据的信息, 避免了权重赋予时的主观性, 并且不受制于样本数量的限 制。[15]结合本次指标评价过程中使用的样本信息和样本 量, 综合考虑后最终选择拥有更好操作性和客观性的摘权 法。

\section{3. 熵权法分析}

由于构建的指标体系中存在四项负向指标, 为了便于 综合评价，先将四项负向指标正向化处理；此外，各个指 标数据的量纲不统一, 若不经过处理直接评价会使结果产 生较大偏差, 所以将全部正向化的指标数据进行归一化处 理, 使得量纲严格相等, 结果如表2所示:

表2 数据正向化、归一化结果。

\begin{tabular}{|c|c|c|c|c|c|}
\hline 指标名称 & 2014 & 2015 & 2016 & 2017 & 2018 \\
\hline 总资产贡献率 & 1.0000 & 0.7862 & 0.6290 & 0.4299 & 0.0000 \\
\hline 成本费用利润率 & 1.0000 & 0.8658 & 0.6242 & 0.4698 & 0.0000 \\
\hline 资产负债率 & 0.7241 & 0.5483 & 0.4414 & 1.0000 & 0.0000 \\
\hline 制造业研发经费投入强度 & 0.0000 & 0.0750 & 0.1375 & 0.3750 & 1.0000 \\
\hline 制造业研发人员投入强度 & 0.0000 & 0.1284 & 0.3853 & 0.5963 & 1.0000 \\
\hline 人均发明专利数 & 0.0000 & 0.3333 & 0.6667 & 1.0000 & 1.0000 \\
\hline 节能环保支出比例 & 0.0000 & 0.5962 & 0.7885 & 0.4615 & 1.0000 \\
\hline 单位工业增加值能耗 & 0.8333 & 1.0000 & 0.5000 & 0.0833 & 0.0000 \\
\hline 单位工业产值废水排放量 & 1.0000 & 1.0000 & 0.0909 & 0.0455 & 0.0000 \\
\hline 单位工业产值固体废物排放量 & 0.0000 & 0.0000 & 0.3333 & 1.0000 & 1.0000 \\
\hline 高技术产业主营业务收入比重 & 0.0000 & 0.7822 & 1.0000 & 0.6931 & 0.4059 \\
\hline 制造业全员劳动生产率 & 0.0000 & 0.1813 & 0.5054 & 0.7598 & 1.0000 \\
\hline 制造业人均产值 & 0.0000 & 0.2178 & 0.4446 & 0.6522 & 1.0000 \\
\hline 制造业500强占比 & 0.0000 & 0.0000 & 0.6000 & 0.8000 & 1.0000 \\
\hline 高技术产业出口总额比重 & 1.0000 & 0.4583 & 0.0000 & 0.2917 & 0.4167 \\
\hline 制造业出口交货值比重 & 1.0000 & 0.0000 & 1.0000 & 0.0000 & 1.0000 \\
\hline 产品质量合格率 & 0.0000 & 0.1877 & 0.3239 & 1.0000 & 0.8721 \\
\hline 制造业人均工资 & 0.0000 & 0.1429 & 0.2500 & 0.5357 & 1.0000 \\
\hline 制造业工资占比 & 1.0000 & 0.7583 & 0.4894 & 0.2961 & 0.0000 \\
\hline 制造业利税总额 & 1.0000 & 0.8710 & 0.9314 & 0.7519 & 0.0000 \\
\hline
\end{tabular}


数据经过正向化、归一化处理后, 根据信息熵公式 $E_{j}=-\ln (n)^{-1} \sum_{i=1}^{n} p_{i j} \ln p_{i j}$, 计算各指标信息熵e, 结果如表3所 示:

表3 各指标信息熵e。

\begin{tabular}{llll}
\hline 指标名称 & 信息熵e & 指标名称 & 信息熵e \\
\hline 总资产贡献率 & 0.8461 & 高技术产业主营业务收入比重 & 0.8448 \\
成本费用利润率 & 0.8484 & 制造业全员劳动生产率 & 0.7913 \\
资产负债率 & 0.8446 & 制造业人均产值 & 0.7986 \\
制造业研发经费投入强度 & 0.6461 & 山东省制造业500强占比 & 0.6973 \\
制造业研发人员投入强度 & 0.7604 & 高技术产业出口总额比重 & 0.8075 \\
人均发明专利数 & 0.8268 & 制造业出口交货值比重 & 0.7055 \\
节能环保支出比例 & 0.8481 & 产品质量合格率 & 0.7654 \\
单位工业增加值能耗 & 0.7485 & 制造业人均工资 & 0.7392 \\
单位工业产值废水排放量 & 0.6048 & 制造业工资占比 & 0.8192 \\
单位工业产值固体废物排放量 & 0.6541 & 制造业利税总额 & 0.8676 \\
\hline
\end{tabular}

计算出各指标信息熵后, 根据权重计算公式 $W_{i}=\frac{1-E_{i}}{20-\sum E_{i}}(\mathrm{i}=1,2, \ldots, 20)$, 可以得到各个指标权重, 结果如表4所示:

表4 熵权法处理后各指标权重w。

\begin{tabular}{llll}
\hline 指标名称 & 权重w & 指标名称 & 权重w \\
\hline 总资产贡献率 & $3.39 \%$ & 高技术产业主营业务收入比重 & $3.42 \%$ \\
成本费用利润率 & $3.34 \%$ & 制造业全员劳动生产率 & $4.60 \%$ \\
资产负债率 & $3.43 \%$ & 制造业人均产值 & $4.44 \%$ \\
制造业研发经费投入强度 & $7.80 \%$ & 制造业500强占比 & $6.67 \%$ \\
制造业研发人员投入强度 & $5.28 \%$ & 高技术产业出口总额比重 & $4.25 \%$ \\
人均发明专利数 & $3.82 \%$ & 制造业出口交货值比重 & $6.49 \%$ \\
节能环保支出比例 & $3.35 \%$ & 产品质量合格率 & $5.17 \%$ \\
单位工业增加值能耗 & $5.54 \%$ & 制造业人均工资 & $5.75 \%$ \\
单位工业产值废水排放量 & $8.71 \%$ & 制造业工资占比 & $3.99 \%$ \\
单位工业产值固体废物排放量 & $7.63 \%$ & 制造业利税总额 & $2.92 \%$ \\
\hline
\end{tabular}

最后, 根据熵权法得出的指标权重, 设 $Z_{l}$ 为第 $\mathrm{i}$ 年的最终得分, 则有 $Z_{l}=\sum_{i}^{20} X_{l i} W_{i}, 2014-2018$ 年山东省制造业高质 量发展状况最终得分如表 5 所示:

表5 2014-2018年山东省制造业高质量发展状况综合评分。

\begin{tabular}{llllll}
\hline 年份 & $\mathbf{2 0 1 4}$ & $\mathbf{2 0 1 5}$ & $\mathbf{2 0 1 6}$ & $\mathbf{2 0 1 7}$ & $\mathbf{2 0 1 8}$ \\
\hline 综合分数 & 0.40195 & 0.40013 & 0.46134 & 0.53347 & 0.63504 \\
\hline
\end{tabular}

总体来看, 在2014-2018五年间, 山东省制造业高质 量发展状况整体呈现良好上升态势, 表明山东省积极响 应了国家提出的制造业高质量发展要求，同时也在努力 实现《中国制造2025》中提出的战略目标。其中创新驱 动、绿色环保和协调发展三个方面尤为突出, 具体表现 在山东省制造业研发经费投入和研发人员投入逐年增加, 节能环保支出比例上涨明显, 单位工业增加值能耗和单 位工业产值废水排放量明显下降, 制造业全员劳动生产 率和制造业人均产值大幅上涨，产品质量合格率从2014 年的 $90.82 \%$ 上涨至 2018 年的 $96.10 \%$, 中国制造业五百强 中山东省制造业的数量从2014年的 62 家增长至2018年的 79 家。
然而, 在山东省制造业高质量发展一片繁荣的景象之 下，也依旧存在一些问题。比如，反映企业全部资产获利 能力的总资产负债率，反映企业所有成本费用获利能力的 成本费用利润率都在连年下降, 制造业利税总额更是呈现 断崖式下跌, 这些问题出现的原因与制造业高质量发展理 念密不可分。制造业高质量发展倡导绿色环保、结构优化 等理念, 为了与相应的理念契合, 山东省对环保不达标的 部分制造业企业停工限产，有些地方更是施行“一刀切”直 接关闭了大批不符合“新动能”标准的企业。例如在2015年 至2017年，山东省临淄地区化工企业从2000多家减少至 300 家左右, 制陶业更是限产 $30 \%$, 裁掉了 $70 \%$ 的产能, 这 也直接导致临淄地区这三年的GDP一直没有超过全省平 均水平。 


\section{5. 结论与建议}

本文基于确立的具有代表性的评价指标，充分利用 2014-2018年的中国统计年鉴、山东省统计年鉴，结合EPS 数据库和国研网等统计网站搜集的数据, 构建了包含质量 效益、创新驱动、绿色环保、协调发展、对外开放和社会 共享六个方面的指标评价体系, 并采用摘权法, 对 2014-2015年五年间山东省制造业高质量发展状况进行评 价。根据综合得分情况可以看出, 在这五年间, 山东省制 造业高质量发展水平整体呈现上升态势，仅在2015年略有 波动, 与此同时, 山东省也在依靠制造业高质量发展这一 发展要求, 努力从“制造大省”向“制造强省”转变, 从“山东 制造”向“山东创造”、“山东智造”转变。

虽然山东省制造业高质量发展整体向好, 但在许多方 面仍有改进的余地。因此本文根据现存的较为明显的问题 提出以下建议:

\section{1. 提前规划部署, 做好衔接工作}

2017年，山东省关闭“散、乱、污”企业十万余家，其 中不乏规模以上工业企业以及正处在盈利期的企业，“老 牛”已经离去, “幼牛”却还未成长，符合标准的新项目至 少要到2021年才能落地投产，断档期的阵痛在所难免。通 过推进新旧动能转换实现制造业高质量发展是一个长期 过程, 处于阵痛期的山东省更应当保持定力, 加大财政扶 持力度, 对处于转型期的企业给予扶持帮助, 同时尽可能 加速新项目的落地投产, 缩短阵痛期, 推动山东省制造业 高质量发展。

\section{2. 简化审批流程, 促进科技转化}

在淘汰落后产能、推动新产能实现制造业高质量发展 的过程中, 由于监管和审批上的不明晰, 导致部分地区出 现了“一刀切”现象, 这虽然使得旧产能得以迅速淘汰, 但 是却导致新产能难以跟进, 严重影响科技成果转化。因此, 山东省相关部门应加强对旧动能产业的监管与帮扶, 努力 做到“应转尽转”，帮助传统产业转型升级而非直接关停; 在新动能项目的审批方面, 应当精简流程, 迅速帮助企业 落实新项目, 减少不必要的资源浪费与消耗。

\section{3. 转变思想观念, 充分吸纳人才}

山东省制造业实力虽然在国内名列前茅, 但在与其他 制造业发达地区的区域竞争中已经落入下风，导致这一现 象的原因是观念保守守成, 改革创新意识欠缺。不可否认, 山东省长期以来满足于制造业强省的身份, 思想保守、缺 乏危机意识, 在大数据互联网时代的潮流中, 没有抓住机 遇推动制造迈向高端化。此外, 人才是制造业企业发展乃 至经济发展的绝对核心因素, 然而在各省市日趋激烈的 “强人大战”中，山东省却略显落寞。然而“人往高处走， 水往低处流”, 愈是有发展前景良好、政策有优势的地方, 愈能吸引人才、留住人才。因此, 山东省应当积极利用恰 当的政策吸收人才、留住人才, 再通过人才优势激发山东 省制造业发展活力, 带动山东省制造业发展, 最终促进全 省经济的发展，最终形成良性循环。

\section{致谢}

作者感谢本次国际会议所有评审专家的建设性意见 与建议, 感谢老师在写作指导和修改方面给予莫大的帮助, 感谢教育部人文社会科学研究项目“融资约束视角下税收 激励对企业创新的影响机理及绩效评价”（项目编号: 16YJC630137) 和山东工商学院研究生科技创新基金项目 “山东省制造业高质量发展指标评价体系研究” (项目编号: 2019YC023）的资助。

\section{参考文献}

[1] 高培勇.理解、把握和推动经济高质量发展 [J].经济学动 态,2019(08):3-9.

[2] 田秋生.高质量发展的理论内涵和实践要求 [J].山东大学学 报(哲学社会科学版),2018(06):1-8.

[3] 林兆木.关于我国经济高质量发展的几点认识[EB/OL].人民 日报年 http://theory.people.com.cn/n1/2018/0117/c40531-29768994. html

[4] 金碚.关于 “高质量发展”的经济学研究 [J]. 中国工业经 济,2018(04):5-18.

[5] 董志强.推动山东经济高质量发展的路径选择 [J]. 现代交 际,2018(20):189-190.

[6] 余泳泽,胡山.中国经济高质量发展的现实困境与基本路径: 文献综述[J].宏观质量研究,2018,6(04):1-17.

[7] 刘友金,周健. “换道超车”:新时代经济高质量发展路径创新 $[\mathrm{J}]$.湖南科技大学学报(社会科学版),2018,21(01):49-57.

[8] 崔宁,陈鸥. 多维度区域经济质量评估模型探究[J]. 财经界(学 术版),2013(08):21-22+118.

[9] 张丽伟,田应奎.经济高质量发展的多维评价指标体系构建 [J].中国统计,2019(06):7-9.

[10] 马茹,罗晖,王宏伟,王铁成.中国区域经济高质量发展评价指 标体系及测度研究 [J].中国软科学,2019(07):60-67.

[11] 张文会,乔宝华.构建我国制造业高质量发展指标体系的几 点思考[J].工业经济论坛,2018,05(04):27-32.

[12] 刘欣欣,孙良泉,全锡良.山东省制造业高质量发展评价体系 研究[J].标准科学,2019(06):121-124.

[13] 王志博.中国区域经济实现高质量发展的思路和政策基于高质量发展的评价指标体系构建与分析 [J]. 全国流通 经济,2019(06):86-87.

[14] 李巧华.新时代制造业企业高质量发展的动力机制与实现 路径 [J].财经科学,2019(06):57-69.

[15] 周俊. 问卷数据分析-破解SPSS的六类分析思路[M]. 北京: 电 子工业出版社,2017. 


\section{作者简介}

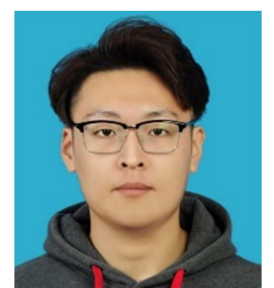

李亦耕, (1997.06-) 男, 硕士研究

生, 研究方向: 审计绩效评价。地址:

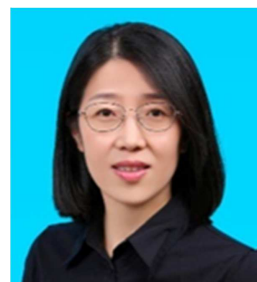

陈智, (1978.09-) 女, 副教授, 会 山东省烟台市莱山区滨海中路191号。

计学博士, 研究方向: 会计信息披露,

绩效评价。地址: 山东省烟台市莱山 区滨海中路191号。 